\title{
Evaluation of autoantibodies against vimentin and $\alpha$-enolase in rheumatoid arthritis patients
}

\author{
Mina Ebrahimi-Rad ${ }^{1}$, Shohreh Khatami ${ }^{1}$, Hadi Akhbari ${ }^{2}$, Hamid Mahmoudzadeh-Niknam ${ }^{3}$, \\ Shirin Valadbeigi ${ }^{1}$, Mahdi Mahmoudi ${ }^{4}$, Alireza Jamshidi ${ }^{4}$, Farhad Riazi-Rad ${ }^{5}$, Reza Saghiri ${ }^{1}$ \\ ${ }^{1}$ Department of Biochemistry, Pasteur Institute of Iran, Tehran, Iran \\ ${ }^{2}$ Department of Rheumatology, Birjand University of Medical Sciences, Iran \\ ${ }^{3}$ Department of Immunology, Pasteur Institute of Iran, Tehran, Iran \\ ${ }^{4}$ Rheumatology Research Center, Tehran University of Medical Sciences, Iran \\ ${ }^{5}$ Department of Immunology, Pasteur Institute of Iran, Tehran, Iran
}

\begin{abstract}
Introduction: Rheumatoid arthritis (RA) is categorized as an autoimmune disease with a frequency of $0.2-1 \%$ worldwide. It is reported that various autoantibodies are produced in the RA population, particularly against citrullinated peptides. Among various candidate markers for RA diagnosis, the citrullinated proteins have the highest specificity and sensitivity for both diagnosis and prognosis of RA. Anti-mutated citrullinated vimentin and $\alpha$-enolase constitute a new class of autoantibodies for early detection of RA.

Material and methods: 45 serum samples and 19 synovial fluid (SF) specimens collected from RA patients were considered for American College of Rheumatology criteria and 20 serum samples and 10 SF specimens were provided from healthy subjects as a control group. To assess the quantity of anti-citrullinated protein antibodies (ACPA), anti-mutated citrullinated vimentin (MCV) and anti$\alpha$-enolase in the serum and SF of RA patients were determined by the enzyme-linked immunosorbent assay (ELISA) method. For the evaluation of disease activity and joint destruction, we used the Disease Activity Score of 28 joints based on erythrocyte sedimentation rate (ESR) Disease Activity Score 28 (DAS28). Furthermore, to measure the molecular weight of vimentin and $\alpha$-enolase, electrophoresis on $10 \%$ SDS-PAGE was performed as described before.

Results: The anti- $\alpha$-enolase level among serum samples from RA patients was significantly higher than in healthy subjects $(4.49 \pm 0.20 \mathrm{ng} / \mathrm{ml} \mathrm{vs} .0 .76 \pm 0.12 \mathrm{ng} / \mathrm{ml})(p<0.001)$. There was a direct relation between $\alpha$-enolase quantity and (rheumatoid factor) RF and C-reactive protein (CRP) levels. The mean ESR value in positive and negative ACPA patients was $38.2 \pm 22.6 \mathrm{~mm} / \mathrm{h}$ and $9.2 \pm 5.8 \mathrm{~mm} / \mathrm{h}$ respectively $(p<0.0001)$. The mean DAS28-ESR was 3.3. The level of anti-MCV in the serum of RA patients $(244.6$ $\pm 53.3 \mathrm{U} / \mathrm{ml})$ was higher than in serum of the healthy group $(148.73 \pm 71.8)(p<0.0001)$. The level of anti-MCV in the SF of patients was $687.5 \pm 148.4 \mathrm{U} / \mathrm{ml}$.

Conclusions: In conclusion, both autoantibodies against MCV and $\alpha$-enolase are two important markers that increase in serum and SF of RA patients and are specific for diagnosis of RA disease.
\end{abstract}

Key words: rheumatoid arthritis, autoantibodies, vimentin, $\alpha$-enolase, anti-citrullinated peptide antibodies, synovial fluid, Disease Activity Score.

\section{Introduction}

Rheumatoid arthritis (RA) is the chronic inflammatory disease with the various ranges of joint disability and ultimately disability of patients. The extent of disability is associated with joint destruction and disease activity. The data on the occurrence of these autoimmune diseases vary depending on the area of the world, e.g. in the 
metanalysis by Alamanos et al. [1] the prevalence in south European countries is 3.3 (range 3.1 to 5.0) cases per 1000, and for developing countries 3.5 (range 2.4 to 3.6).

However, the early pathogenesis of this systematic disease is ambiguous [2]. Powerful genetic risk factors associated with anti-citrullinated protein antibodies (ACPA)-positive RA are HLA-DR1 and HLA-DR4. It is reported that various autoantibodies are produced in the RA population, particularly against ACPA. Citrullinated peptides are synthesized through posttranslational processes that convert arginine to citrulline. This residue conversion is done by peptidyl arginine deiminases [3]. There are several autoantibodies against citrullinated peptides including peptides derived from citrullinated fibrinogen $b$ [4], citrullinated $\alpha$-enolase peptide [5], citrullinated vimentin [6], and citrullinated tenascin-C [7]. Among discrepant candidate markers for RA diagnosis, the citrullinated proteins have the highest specificity and sensitivity for both diagnosis and prognosis of RA [3].

Anti-mutated citrullinated vimentin (MCV) is a new class of autoantibodies for early detection of RA [8]. Vimentin is formed from the intermediate filament of cytoskeleton structure and expressed in various cells such as monocytes, endothelial cells and cells with mesenchymal origin $[9,10]$. Moreover, macrophage-like and fibroblast-like synoviocytes located in synovial joints contain abundant vimentin. These two types of cells are implicated in RA pathogenesis [10]. Vimentin is citrullinated in RA patients, causing activation of T-lymphocytes via attaching to HLA-DR4 of antigen-presenting cells [11].

A previous study found approximately $95 \%$ specificity and $78 \%$, sensitivity of anti-MCV for RA monitoring both for diagnosis and prognosis [12]. Furthermore, anti-MCV was detected in about $20-25 \%$ of RA in early stage but in $47 \%$ of more advanced disease stages $[3,13]$.

Citrullinated $\alpha$-enolase is detected among patients suffering from RA. $\alpha$-enolase has several roles in the cells such as a glycolytic enzyme, a heat shock protein, receptors for plasminogen, etc. [14]. The expression of $\alpha$-enolase is found in hypoxia, inflammation and cell differentiation. Furthermore, this enzyme was detected in the inflammatory joints of RA patients [15]. Although the quantity of this enzyme increases in various infectious and inflammatory diseases [14], the presence of autoantibodies against citrullinated $\alpha$-enolase is observed only in RA [16].

The antibodies against the citrullinated form of this enzyme were reported in up to $62 \%$ of RA cases both in serum and with a higher amount in synovial fluids [5, 17]. The production of these antibodies is directly correlated with the presence of specific PTPN22W polymorphism and HLA alleles [18]. On the other hand, other RA risk factors and the therapeutic regimen are involved in creation of antibodies against citrullinated $\alpha$-enolase [11].
The aim of the current study was to assess the status of autoantibodies against two proteins, vimentin and $\alpha$-enolase, in the serum and synovial fluid (SF) samples from Iranian RA patients and compare them to healthy subjects.

\section{Material and methods \\ Patients and serum samples}

The current study was a cross-sectional assessment, carried out in Tehran, Iran. Forty-five serum samples and 19 SF specimens were collected from RA patients referred to Loghman Hospital, Imam Khomeini Hospital and Iran Rheumatism Center Clinic with symptoms duration of 2 years or less (disease duration $\leq 2$ years), who had been referred to the arthritis clinic between February 2014 and March 2016. In addition, 20 serum samples and 10 SF specimens were provided from healthy subjects as a control group.

Diagnosis of RA was established by rheumatologist according to ACR/EULAR 2010 criteria. A search was conducted based on randomized controlled experiments and diagnostic accuracy of systematic reviews of such study types assessing the clinical diagnostic validity of clinical assessment of any joints.

Moreover, baseline laboratory investigations included erythrocyte sedimentation rate (ESR), C-reactive protein (CRP), and ACPA were performed. Anti-citrullinated protein antibodies were measured using the standard ELISA method. Negativity or positivity for ACPA was defined as $<200 \mathrm{U} / \mathrm{ml}$ or $\geq 200 \mathrm{U} / \mathrm{ml}$, respectively. The disease activity was assessed by determination of swelling and pain of 28 joints and results of CRP and presented as a result of Disease Activity Score 28 (DAS28-ESR).

The presented study obtained local Bioethics Committee approval.

\section{Sample collection}

To prepare serum specimens, a blood sample from each subject, both patients and controls, was centrifuged at $3000 \mathrm{rpm}$ for $15 \mathrm{~min}$ and the serum fraction were transferred to new tubes and stored at $-80^{\circ} \mathrm{C}$ for further assessments.

\section{Alpha-enolase analysis}

To evaluate the antibody against $\alpha$-enolase (anti$\alpha$-enolase) among RA patients, the ELISA method was applied. The level of anti- $\alpha$-enolase in serum and SF samples was analyzed using a human $\alpha$-enolase ELISA kit (ENO1/ENO1L1/MBPB1/MPB1) in accordance with the manufacturer's guideline. 
Table I. Demographics and clinical characteristics of the rheumatoid arthritis patients

\begin{tabular}{|lc|}
\hline Characteristics & $p$-value \\
\hline Age (years) & 47.51 \\
\hline Female $(\%)$ & 78 \\
\hline Duration of RA (years) & $\leq 2$ \\
\hline RF positive (\%) & 71.3 \\
\hline CRP $(\mathrm{mg} / \mathrm{l})$ & $12.36 \pm 8.32$ \\
\hline ESR $(\mathrm{mm} / \mathrm{h})$ & $38.2 \pm 22.6$ \\
\hline ACPA positive $(\%)$ & 69 \\
\hline Methotrexate $(\%)$ & 51.5 \\
\hline Corticosteroid $(\%)$ & 35.2 \\
\hline Tender joint count $(T J C 28) \pm S D$ & $7.42 \pm 6.23$ \\
\hline DAS28-ESR & 3.3 \\
\hline
\end{tabular}

$R A$ - rheumatoid arthritis, $R F$ - rheumatoid factor, CRP - C-reactive protein, ESR - erythrocyte sedimentation rate, ACPA - anti-citrullinated protein antibodies, DAS28 - Disease Activity Score 28.

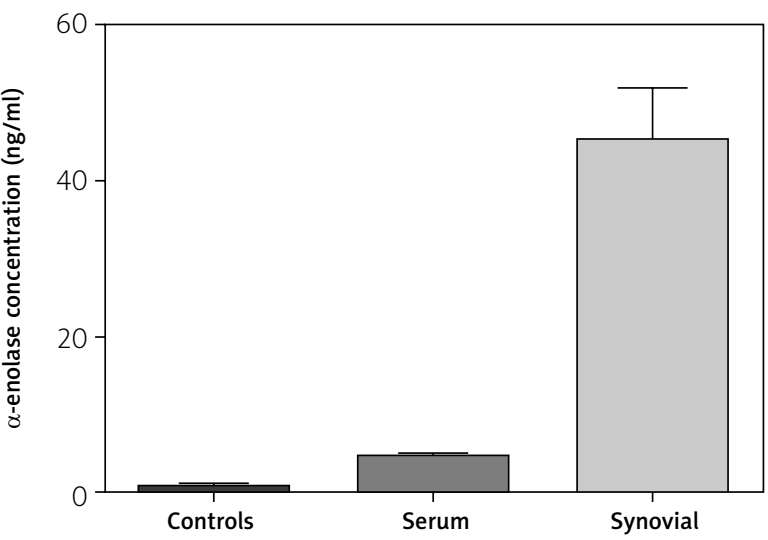

Fig. 1. Anti- $\alpha$-enolase concentrations in serum and synovial fluid of healthy and patient group.

Briefly, $100 \mu \mathrm{l}$ of each sample and standards were separately added to each well. After two hours' incubation at $37^{\circ} \mathrm{C}$, the solution of each well was removed and then $100 \mu \mathrm{l}$ of biotinlabeled antibody was added and it was incubated for one hour at $37^{\circ} \mathrm{C}$. After precise washing of each well, $100 \mu \mathrm{l}$ of Avidin-HRP was added to each well for one-hour incubation at $37^{\circ} \mathrm{C}$. In the next step, $9 \mu \mathrm{l}$ of TMB, as the HRP substrate, was added to wells followed by $15-20$ min incubation at $37^{\circ} \mathrm{C}$ in a dark place. The $50 \mu$ l solution was applied to stop the enzymatic reaction. Finally, the absorbance of each well was measured at $450 \mathrm{~nm}$ using an Anthos 2020 ELISA reader (Biochrom Ltd, UK).

Moreover, to identify the presence and molecular weight of $\alpha$-enolase in serum and SF samples, electrophoresis on $10 \%$ SDS-PAGE was performed. During SDS PAGE, all proteins migrate toward the anode (the posi- tively charged electrode). SDS-treated proteins have very similar charge-to-mass proportions, and similar forms. within PAGE, the rate of migration of SDS-treated proteins is efficiently distinguished by molecular weight. Finally, to visualize the protein bands, the SDS-PAGE was stained using Coomassie blue G250.

\section{Vimentin evaluation}

To assess the quantity of anti-MCV in the serum and SF of RA patients, the Human Anti-Mutated Citrullinated Vimentin Antibody ELISA kit was applied. The procedure was performed based on the manufacturer's guideline. All the steps were similar to the protocol described for anti- $\alpha$-enolase.

Furthermore, to evaluate the molecular weight of vimentin in serum and SF samples, electrophoresis on 10\% SDS-PAGE was performed as described before.

\section{Statistical analysis}

To compute the statistically significant differences between two tested groups, STATA 11 software was used.

To survey the factors correlated with anti- $\alpha$-enolase and vimentin, linear regression was performed. The $p$-value lower than 0.05 was considered to indicate a significant result.

The disease activity score, swollen joints, anti-vimentin and anti-MCV levels were analyzed using Pearson's correlation t-test and Mann-Whitney statistical test.

\section{Results}

In the current study, the alteration in the anti- $\alpha$-enolase and vimentin was surveyed among RA patients. The studied patients group characteristics are presented in Table I.

Thirty-five (78\%) RA cases and 8 (40\%) healthy subjects were female among serum samples. The mean DAS28 was 3.3. The mean ESR in positive and negative ACPA patients was $38.2 \pm 22.6$ and $9.2 \pm 5.8 \mathrm{~mm} / \mathrm{h}$ respectively $(p<0 / 0001)$ (Table I).

The level of anti- $\alpha$-enolase among serum samples from patients was significantly higher than in healthy subjects $(4.49 \pm 0.20 \mathrm{ng} / \mathrm{ml}$ vs. $0.76 \pm 0.12 \mathrm{ng} / \mathrm{ml})(p<0.001)$ (Fig. 1).

Outcomes from linear regression analysis showed that the anti- $\alpha$-enolase quantity of RA serum $(3.73 \mathrm{ng} / \mathrm{ml})$ was higher than in healthy serum (Table II).

Despite the lack of correlation between age and anti- $\alpha$-enolase level, anti- $\alpha$-enolase in males was 1.07 fold lower than in females ( $p=0.047$ ) (Table III).

In addition, regardless of the disease status, there was direct relation between anti- $\alpha$-enolase level and rheumatoid factor (RF) and CRP levels. One-unit in- 
Table II. Relation between vimentin and $\alpha$-enolase activity in rheumatoid arthritis sera

\begin{tabular}{|c|c|c|c|c|}
\hline Parameters & Coef. & Std. err. & $P>t$ & $95 \% \mathrm{Cl}$ \\
\hline \multicolumn{5}{|l|}{$\alpha$-enolase } \\
\hline $\begin{array}{l}\text { Status } \\
\text { (Patient/healthy) }\end{array}$ & 3.733 & 0.309 & $<0.001$ & $3.115-4.351$ \\
\hline cons & 0.755 & 0.257 & 0.005 & $0.241-1.269$ \\
\hline \multicolumn{5}{|l|}{ Anti-MCV } \\
\hline $\begin{array}{l}\text { Status } \\
\text { (Patient/healthy) }\end{array}$ & 95.89 & 26.94 & 0.000 & $-7.35-100.33$ \\
\hline _cons & 148.73 & 22.41 & 0.001 & $103.93-193.53$ \\
\hline
\end{tabular}

Anti-MCV - anti-mutated citrullinated vimentin.

Table III. Relation between vimentin and $\alpha$-enolase activity in serum of both healthy and patient group with age and gender

\begin{tabular}{|lcccc|}
\hline Parameters & Coef. & Std. err. & $P>t$ & $95 \% \mathrm{Cl}$ \\
\hline$\alpha$-enolase & & & & \\
\hline Age & 0.0246133 & 0.0225599 & 0.279 & $-0.020-0.07$ \\
\hline Gender & -1.074312 & 0.5308883 & 0.047 & $-2.14-0.01$ \\
\hline cons & 2.565106 & 1.095234 & 0.022 & $0.36-4.75$ \\
\hline Anti-MCV & & & & \\
\hline Age & -0.97 & 1.06 & 0.367 & $-3.09-1.16$ \\
\hline Gender & -8.27 & 29.54 & 0.780 & $-67.34-50.79$ \\
\hline cons & 191.49 & 47.78 & 0.001 & $95.95-287.03$ \\
\hline
\end{tabular}

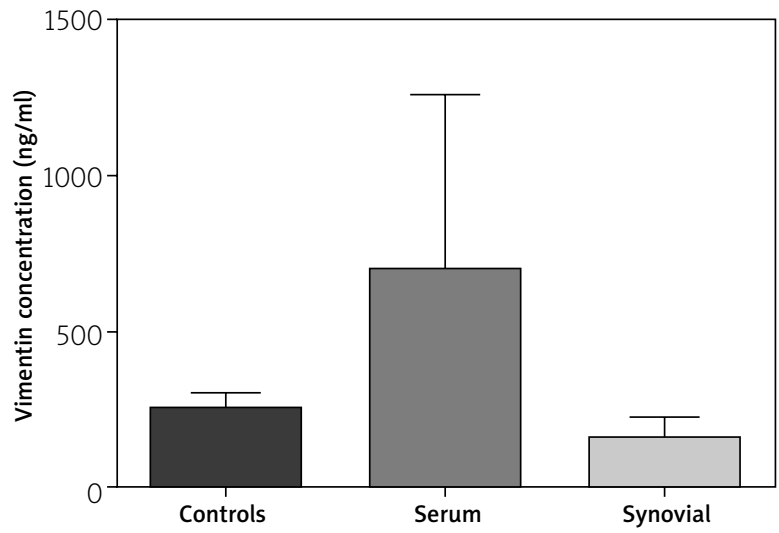

Fig. 2. Comparison of anti-mutated citrullinated vimentin concentrations in serum and synovial fluid (healthy and patient group).

crease in RF and CRP level caused an increase of 0.012 and 0.022 units in the anti- $\alpha$-enolase level $(p=0.001$ and $p=0.009$, respectively).

Mean level of anti- $\alpha$-enolase in SF of patients (44.92 $\pm 1.61 \mathrm{ng} / \mathrm{ml}$ ) was significantly higher than in the healthy group $(0.55 \pm 0.09 \mathrm{ng} / \mathrm{ml})(p<0.001)$ (Fig. 1).

The only variable affecting the anti- $\alpha$-enolase level in the SF is RA disease. The anti- $\alpha$-enolase levels of RA patients' SF were 43.95 units more than in controls.

The levels of anti-MCV in the serum of RA patients $(244.6 \pm 53.3 \mathrm{U} / \mathrm{ml})$ was higher than in serum of healthy groups $(148.73 \pm 71.8 \mathrm{U} / \mathrm{ml})(p<0.0001)$. The level of anti-MCV in the SF of patients was $471 \pm 24$ (U/ml) (Fig. 2).

Furthermore, no significant correlation was observed between the level of anti-MCV age and gender in tested groups.
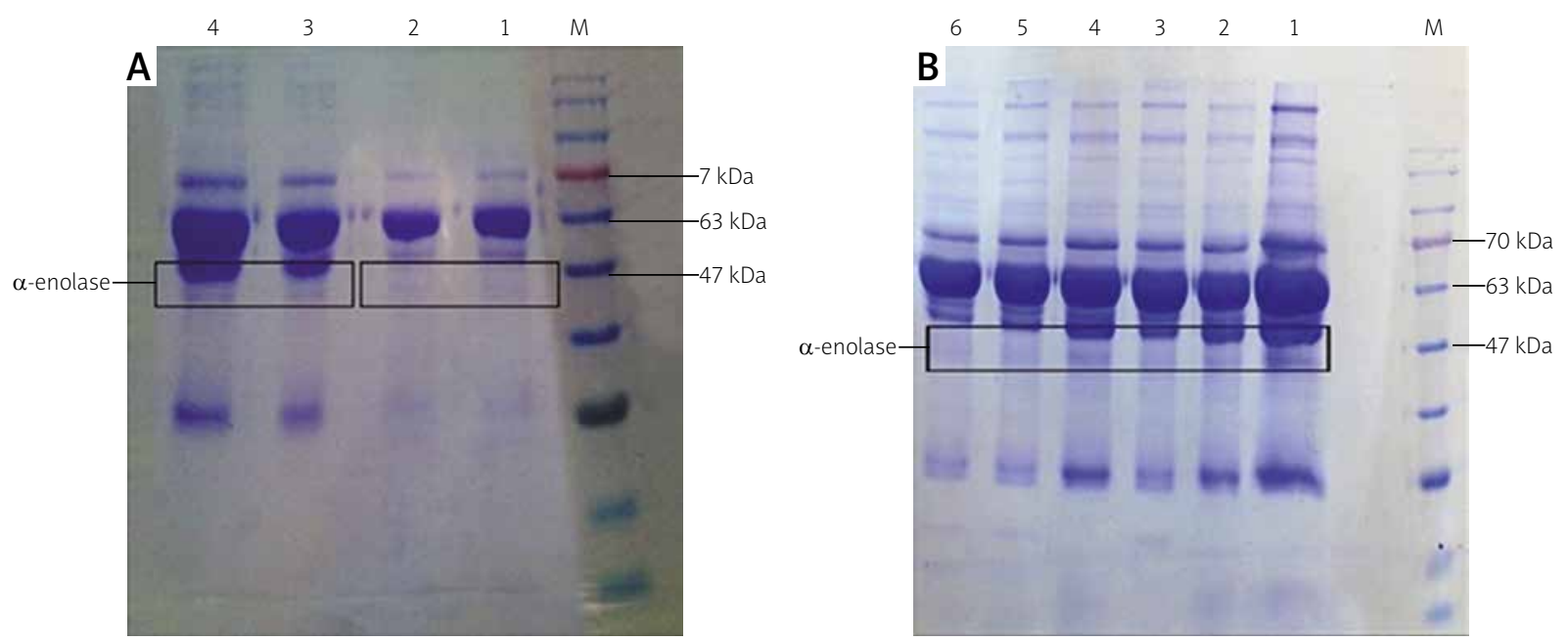

Fig. 3. Evaluation of enzyme in serum (A) and synovial fluid (SF) (B) on 10\% SDS-PAGE. The molecular weight of $\alpha$-enolase is about $47 \mathrm{kDa}$. In (A), lanes 1 and 2 indicate healthy serum samples, and lanes 3 and 4 belong to the rheumatoid arthritis (RA) serum samples (B). Lane $M$ indicates protein marker. All lanes indicate the SF samples from RA patients. 

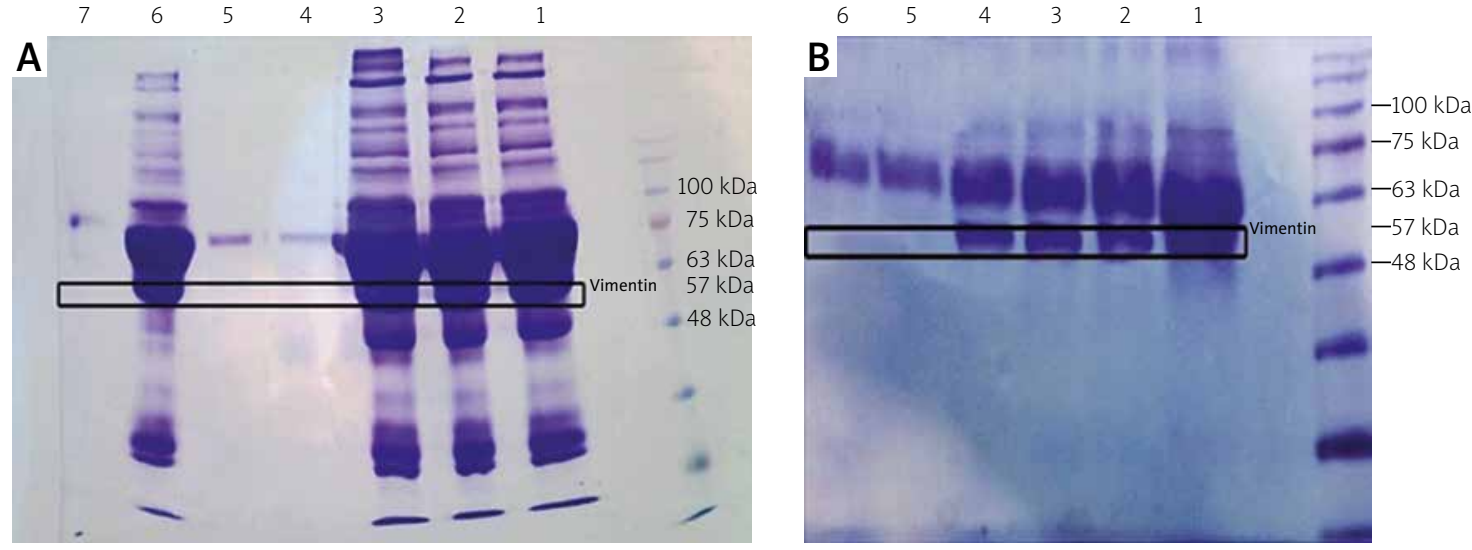

Fig. 4. Evaluation of vimentin in serum (A) and synovial fluid (SF) (B) on 10\% SDS-PAGE. The molecular weight of vimentin is about $57 \mathrm{kDa}$. In (a), lanes 1, 2, 3 and 6 indicate rheumatoid arthritis (RA) serum samples, and lanes 4, 5 and 7 belong to the healthy serum samples. In (b) lanes 1, 2, 3 and 4 indicate RA SF specimens, and lanes 5 and 6 belong to the healthy SF samples.

As illustrated in Figure 3, $\alpha$-enolase protein bands with the molecular weight of $47 \mathrm{kDa}$ were seen in the serum (A) and SF (B) samples collected from RA patients but such a band was not seen in the healthy samples.

In addition, as depicted in Figure 4, vimentin bands $(57 \mathrm{kDa})$ were detected in the serum $(A)$ and SF (B) samples of RA cases, but the healthy samples had no band in this region.

\section{Discussion}

Rheumatoid arthritis is an autoimmune disease with a wide range of clinical manifestations and different grades of severity in different patients. As a consequence of the inflammatory process in the course of RA, mild to severe damage of the joints and their disability are observed. Thus, recognition and screening the patients in the early stage of RA could be helpful for the response to treatment and recovery. The function of ability was evaluated by disease activity in early RA and by joint destruction later in the disease course.

It was found that an increase in the DAS28 had a mild effect on hand joints' function when initially at the beginning of the assessment joint damage was present [19]. Higher baseline DAS28 was able to predict the requirement for procedures such as arthroplasty and synovectomy of the affected joints with persistent synovium hyperplasia.

Forthis purpose, introducing specific markers is necessary to detect subjects with RA. The presence of autoantibodies against various citrullinated proteins has been confirmed as an effective serological indicator for RA detection. These autoantibodies are more accurate and specific than other inflammatory factors such as in- creased RF and CRP in serum of RA patients [20]. In the present study we assessed the presence of two important autoantibodies against MCV and $\alpha$-enolase in both serum and SF in RA patients.

Recently, it was confirmed that ACPA appear in serum of RA patients earlier than anti-MCV antibodies (approximately 4 years earlier), before symptoms onset [21-23]. The anti-MCV assay is more sensitive but ACPA is more specific for RA diagnosis. Finally, based on a literature review, antibodies against MCV are a significantly potent predictive marker to identify the patients before appearance of full-blown RA disease [2].

Autoantibodies against vimentin play an important role in the arthritogenic process as well as in RA pathogenesis [24]. In accordance with the meta-analysis, the sensitivity and specificity of anti-MCV antibodies for RA diagnosis were $77 \%$ and $89 \%$ in comparison with healthy subjects, respectively [25].

Two previous studies reported the incidence of antibodies against MCV from $69.7 \%$ to $81 \%$ in Mexican RA patients $[26,27]$. Furthermore, in the work by Martínez et al. [28], the prevalence of these antibodies was $81.8 \%$ in early stage RA and $88.2 \%$ in established RA. In the Egyptian study, the serum level of anti-MCV in RA patients $(135.82 \pm 126.81 \mathrm{U} / \mathrm{ml})$ was significantly higher than in the healthy group (13.63 $\pm 8.48 \mathrm{U} / \mathrm{ml})$ [29]. The authors reported $84 \%$ sensitivity and $80 \%$ specificity for these antibodies; these results were significantly lower than ACPA (100\%) in the cited study. Despite the lack of correlation between anti-MCV and clinical symptoms, this parameter was related to ACPA [29].

Our study is consistent with previous research performed by El Shazly et al. [29], Wagner et al. [30] and Engelmann et al. [31] and showed that the quantity of 
serum anti-MCV had no association with the gender or age. The level of anti-MCV in the work of Wagner et al. [30] was $308.344 \pm 425.578 \mathrm{U} / \mathrm{ml}$ and also had no correlation with CRP and ESR.

Saulot et al. [16] found that the sera of RA patients contain autoantibodies against $\alpha$-enolase in the early stage. Although the presence of autoantibodies against this enzyme was reported in the previous studies performed on other autoimmune diseases including lupus erythematosus [32], primary biliary cirrhosis, primary sclerosing cholangitis [33] and so on, findings from western blot assay of sera from RA patients showed exclusively $50 \mathrm{kDa}$ proteins without their appearance among other autoimmune diseases. Therefore, this specific $50 \mathrm{kDa}$ protein, the autoantibody against $\alpha$-enolase, was considered as a specific biomarker for diagnosis of the early stage of RA.

On the other hand, approximately, $50 \%$ of RA patients who had autoantibodies against $\alpha$-enolase were RF and ACPA negative. Furthermore, this antibody is involved in the pathogenesis of RA and results in disease deterioration [16]. In another study performed by Kinloch et al. [34], the frequency of autoantibodies against citrullinated $\alpha$-enolase in the RA patients was $46 \%$ while $15 \%$ of healthy subject showed autoantibodies against citrullinated or uncitrullinated $\alpha$-enolase. Lundberg et al. [5] reported that a specific epitope, named citrullinated-enolase-peptide-1 (CEP-1), is responsible for creating autoantibodies against $\alpha$-enolase exclusively in RA patients. Similar to other studies, we observed higher levels of antibody against citrullinated $\alpha$-enolase both in serum and SF in RA patients compared to healthy controls.

\section{Conclusions}

The present study indicates both autoantibodies (against MCV and $\alpha$-enolase) as important markers that increase in serum and SF of RA patients and are specific for disease diagnosis.

The authors declare no conflict of interest.

\section{References}

1. Alamanos Y, Voulgari PV, Drosos AA. Incidence and prevalence of rheumatoid arthritis, based on the 1987 American College of Rheumatology criteria: a systematic review. Semin Arthritis Rheum 2006; 36: 182-188, DOI: 10.1016/j.semarthrit. 2006. 08.006.

2. Kuna AT. Mutated citrullinated vimentin antibodies in rheumatoid arthritis. Clin Chim Acta 2012; 413: 66-73, DOI: 10.1016/ j.cca.2011.10.020.

3. Schwenzer A, Quirke AM, Marzeda AM, et al. Association of Distinct Fine Specificities of Anti-Citrullinated Peptide Anti- bodies With Elevated Immune Responses to Prevotella intermedia in a Subgroup of Patients With Rheumatoid Arthritis and Periodontitis. Arthritis Rheumatol 2017; 69: 2303-2313, DOI: 10.1002/art.40227.

4. Masson-Bessiere C, Sebbag M, Girbal-Neuhauser E, et al. The major synovial targets of the rheumatoid arthritis-specific antifilaggrin autoantibodies are deaminated forms of the alphaand beta-chains of fibrin. J Immunol 2001; 166: 4177-4184, DOI: 10.4049/jimmunol.166.6.4177.

5. Lundberg K, Kinloch A, Fisher BA, et al. Antibodies to citrullinated alpha-enolase peptide 1 are specific for rheumatoid arthritis and cross-react with bacterial enolase. Arthritis Rheum 2008; 58: 3009-3019, DOI: 10.1002/art.23936.

6. Vossenaar ER, Després N, Lapointe E, et al. Rheumatoid arthritis specific anti-Sa antibodies target citrullinated vimentin. Arthritis Res Ther 2004; 6: R142-150, DOI: 10.1186/ar1149.

7. Schwenzer A, Jiang $X$, Mikuls TR, et al. Identification of an immunodominant peptide from citrullinated tenascin- $C$ as a major target for autoantibodies in rheumatoid arthritis. Ann Rheum Dis 2016; 75: 1876-1883, DOI: 10.1136/annrheumdis-2015-208495.

8. Liu X, Jia R, Zhao J, Li Z. The role of anti-mutated citrullinated vimentin antibodies in the diagnosis of early rheumatoid arthritis. J Rheumatol 2009; 36: 1136-1142, DOI: 10.3899/jrheum.080796.

9. Strelkov SV, Herrmann H, Aebi U. Molecular architecture of intermediate filaments. Bioessays 2003; 25: 243-251, DOI: 10.1002/bies.10246

10. Meyer LH, Franssen L, Pap T. The role of mesenchymal cells in the pathophysiology of inflammatory arthritis. Best Pract Res Clin Rheumatol 2006; 20: 969-981, DOI: 10.1016/ j.berh.2006.06.005.

11. Fisher BA, Plant D, Brode M, et al. Antibodies to citrullinated alpha-enolase peptide 1 and clinical and radiological outcomes in rheumatoid arthritis. Ann Rheum Dis 2011; 70: 10951098, DOI: 10.1136/ard.2010.138909.

12. Ursum J, Nielen MM, van Schaardenburg D, et al. Antibodies to mutated citrullinated vimentin and disease activity score in early arthritis: a cohort study. Arthritis Res Ther 2008; 10: R12, DOI: 10.1186/ar2362.

13. Menard HA, Lapointe E, Rochdi MD, Zhou ZJ. Insights into rheumatoid arthritis derived from the Sa immune system. Arthritis Res 2000; 2: 429-432, DOI: 10.1186/ar122.

14. Terrier B, Degand N, Guilpain P, et al. Alpha-enolase: a target of antibodies in infectious and autoimmune diseases. Autoimmun Rev 2007; 6: 176-182, DOI: 10.1016/j.autrev.2006.10.004.

15. Kinloch A, Lundberg K, Wait R, et al. Synovial fluid is a site of citrullination of autoantigens in inflammatory arthritis. Arthritis Rheum 2008; 58: 2287-2295, DOI: 10.1002/art.23618.

16. Saulot V, Vittecoq O, Charlionet R, et al. Presence of autoantibodies to the glycolytic enzyme alpha-enolase in sera from patients with early rheumatoid arthritis. Arthritis Rheum 2002; 46: 1196-1201, DOI: 10.1002/art.10252.

17. Snir O, Widhe M, von Spee C, et al. Multiple antibody reactivities to citrullinated antigens in sera from patients with rheumatoid arthritis: association with HLA-DRB1 alleles. Ann Rheum Dis 2009; 68: 736-743, DOI: 10.1136/ard.2008.091355.

18. Mahdi $\mathrm{H}$, Fisher BA, Kallberg $\mathrm{H}$, et al. Specific interaction between genotype, smoking and autoimmunity to citrullinated 
alpha-enolase in the etiology of rheumatoid arthritis. Nat Genet 2009; 41: 1319-1324, DOI: 10.1038/ng.480.

19. Goldblatt F, Isenberg DA. New therapies for rheumatoid arthritis. Clin Exp Immunol 2005; 140: 195-204, DOI: 10.1111/j.13652249.2005.02744.x.

20. Klareskog L, Catrina Al, Paget S. Rheumatoid arthritis. Lancet 2009; 373: 659-672, DOI: 10.1016/S0140-6736(09)60008-8.

21. Turesson C, Bergstrom U, Jacobsson LT, et al. Increased cartilage turnover and circulating autoantibodies in different subsets before the clinical onset of rheumatoid arthritis. Ann Rheum Dis 2011; 70: 520-522, DOI: 10.1136/ard.2010.131896.

22. Rantapää-Dahlqvist $S$, de Jong BA, Berglin E, et al. Antibodies against cyclic citrullinated peptide and IgA rheumatoid factor predict the development of rheumatoid arthritis. Arthritis Rheum 2003; 48: 2741-2749, DOI: 10.1002/art.11223.

23. Nielen MM, van Schaardenburg D, Reesink HW, et al. Specific autoantibodies precede the symptoms of rheumatoid arthritis: a study of serial measurements in blood donors. Arthritis Rheum 2004; 50: 380-386, DOI: 10.1002/art.20018.

24. Van Steendam K, Tilleman K, Deforce D. The relevance of citrullinated vimentin in the production of antibodies against citrullinated proteins and the pathogenesis of rheumatoid arthritis. Rheumatology (Oxford) 2011; 50: 830-837, DOI: 10.1093/rheumatology/keq419.

25. Qin X, Deng Y, Xu J, et al. Meta-analysis: diagnostic value of serum anti-mutated citrullinated vimentin antibodies in patients with rheumatoid arthritis. Rheumatol Int 2011; 31: 785 794, DOI: 10.1007/s00296-009-1343-3.

26. Diaz-Toscano ML, Olivas-Flores EM, Zavaleta-Muñiz SA, et al, Comparison of two assays to determine anti-citrullinated peptide antibodies in rheumatoid arthritis in relation to other chronic inflammatory rheumatic diseases: assaying anti-mod- ified citrullinated vimentin antibodies adds value to secondgeneration anti-citrullinated cyclic peptides testing. Biomed Res Int 2014; 2014:198198, DOI: 10.1155/2014/198198.

27. Gonzalez-Lopez L, Rocha-Muñoz AD, Ponce-Guarneros M, et al. Anti-cyclic citrullinated peptide (anti-CCP) and anti-mutated citrullinated vimentin (anti-MCV) relation with extra-articular manifestations in rheumatoid arthritis. J Immunol Res 2014; 2014: 536050, DOI: 10.1155/2014/536050.

28. Martinez G, Gómez JA, Bang H, et al. Carbamylated vimentin represents a relevant autoantigen in Latin American (Cuban) rheumatoid arthritis patients. Rheumatol Int 2016; 36: 781791, DOI: 10.1007/s00296-016-3472-9.

29. El Shazly RI, Anwar Hussein S, Zaki Raslan H, Elgogray AA. Anti-mutated citrullinated vimentin antibodies in rheumatoid arthritis patients: Relation to disease activity and manifestations. The Egyptian Rheumatologist 2014; 36: 65-70.

30. Wagner E, Skoumal M, Bayer PM, Klaushofer K. Antibody against mutated citrullinated vimentin: a new sensitive marker in the diagnosis of rheumatoid arthritis. Rheumatol Int 2009; 29: 1315-1321, DOI: 10.1007/s00296-009-0854-2.

31. Engelmann R, Brandt J, Eggert $M$, et al. The anti-mutated citrullinated vimentin response classifies patients with rheumatoid arthritis into broad and narrow responders. J Rheumatol 2009; 36: 2670-2674, DOI: 10.3899/jrheum.081263.

32. Pratesi F, Moscato S, Sabbatini A, et al. Autoantibodies specific for alpha-enolase in systemic autoimmune disorders. J Rheumatol 2000; 27: 109-115.

33. Pancholi V. Multifunctional alpha-enolase: its role in diseases. Cell Mol Life Sci 2001; 58: 902-920, DOI: 10.1007/pl00000910.

34. Kinloch A, Tatzer $V$, Wait $R$, et al. Identification of citrullinated alpha-enolase as a candidate autoantigen in rheumatoid arthritis. Arthritis Res Ther 2005; 7: R1421-R1429, DOI: 10.1186/ar1845. 